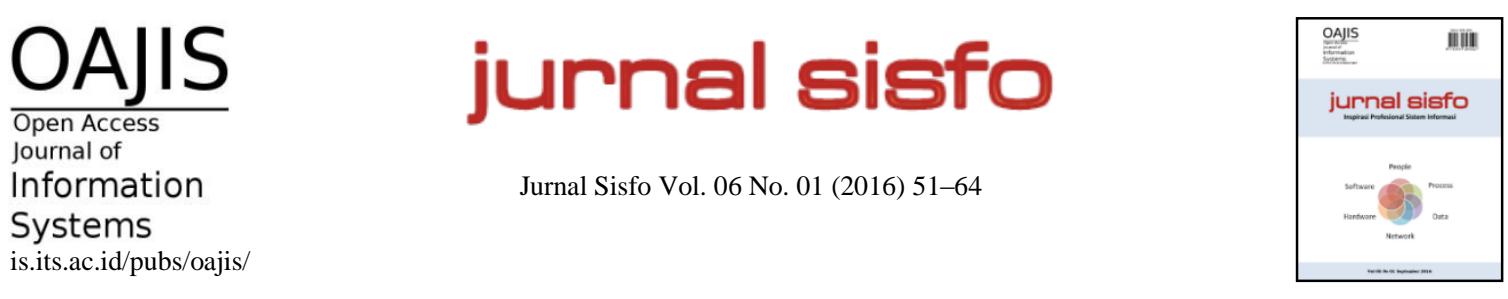

\title{
Integrasi Sistem Informasi: Akses Informasi Sumber Daya Fasilitas Kesehatan dalam Pelayanan Rujukan
}

\author{
Guardian Y. Sanjaya *, Ni’mah Hanifah, Hendri K. Prakosa, Lutfan Lazuardi \\ Departemen Kebijakan dan Pelayanan Kesehatan, Fakultas Kedokteran, Universitas Gadjah Mada
}

\begin{abstract}
Utilization of health services is increasing in the era of National Health Insurance (JKN) through referral service. Unfortunately, lack of information of health facilities resources, leading to sub optimal referral services and emergency care. On the other hand, information and communication technology can facilitate referral services through the provision of information of health facilities resource in an area. This research aimed to design an integrated information system to support a referral service and emergency care in DI Yogyakarta province. A qualitative research was conducted in order to analyze the need of information of health facilitiy resources, designing integrated information system and to provide information of health facilities resources electronically. Most of the health facilities, both primary care and hospitals already have an electronic information system. Integrated information system was developed to integrate data of health facilities resource from various existing systems thorugh the web service technology.
\end{abstract}

Keywords: integrated information system, health facility resources, referral services, web service

\begin{abstract}
Abstrak
Di era Jaminan Kesehatan Nasional (JKN), utilisasi pelayanan kesehatan semakin tinggi melalui pelayanan rujukan berjenjang. Sayangnya ketersediaan informasi sumber daya fasilitas kesehatan menyebabkan pelayanan rujukan dan kegawat-daruratan kurang optimal. Disisi lain, teknologi informasi dan komunikasi dapat memfasilitasi pelayanan rujukan melalui penyediaan informasi sumber daya fasilitas kesehatan di suatu wilayah. Penelitian ini bertujuan untuk merancang sistem informasi terintegrasi untuk mendukung pelayanan rujukan dan kegawat-daruratan medis di DI Yogyakarta. Penelitian dilakukan secara kualitatif untuk menganalisa kebutuhan informasi sumber daya fasilitas kesehatan, merancang integrasi antar sistem informasi secara elektronik, serta penyediaan layanan informasi sumber daya fasilitas kesehatan bagi pengguna. Sebagian besar fasilitas kesehatan, baik layanan primer maupun rumah sakit sudah memiliki sistem informasi elektronik. Sistem informasi terintegrasi dikembangkan untuk mengumpulkan data sumber daya fasilitas kesehatan, dengan mengintegrasikan berbagai macam sistem yang digunakan melalui teknologi web service.
\end{abstract}

Kata kunci: sistem informasi terintegrasi, sumber daya fasiltias kesehatan, pelayanan rujukan, web service

(C) 2016 Jurnal SISFO.

Histori Artikel : Disubmit 5 April 2016; Diterima 25 Juni 2016; Tersedia online 29 Agustus 2016

\footnotetext{
* Corresponding Author

Email address: gysanjaya@ugm.ac.id (Guardian Y. Sanjaya)
} 


\section{Pendahuluan}

Di era Jaminan Kesehatan Nasional (JKN), pelayanan kesehatan rujukan perorangan dilakukan secara berjenjang sesuai dengan Peraturan Menteri Kesehatan No. 01 tahun 2012. Layanan tingkat primer seperti Puskesmas, dokter praktek keluarga, klinik, menjadi tempat pertama kali pasien kontak dengan tenaga kesehatan, kecuali dalam kondisi gawat darurat. Dokter layanan primer bertanggung jawab terhadap kebutuhan rujukan pasien ke pelayanan tingkat sekunder (rumah sakit tipe D, C dan B). Sedangkan dokter di tingkat sekunder bertanggung jawab terhadap kebutuhan rujukan pasien ke pelayanan tersier baik rumah sakit tipe A dan B Pendidikan [1].

Berbagai pendekatan dilakukan untuk memaksimalkan peran layanan primer sebagai penapis pelayanan rujukan. Antara lain mendeskripsikan kembali kompetensi dokter layanan primer [2], membatasi klaim rumah sakit dengan diagnosis yang seharusnya kompetensi layanan primer dan pengembangan regionalisasi pelayanan rujukan di daerah [3] dan program rujuk balik pasien dengan penyakit kronis [4]. Sayangnya pelayanan rujukan belum berjalan dengan ideal. Pasien masih cenderung untuk langsung mencari pelayanan kesehatan di fasilitas kesehatan sekunder dan bahkan tersier untuk kasus-kasus yang ringan. Beberapa referensi juga menunjukkan adanya permasalahan komunikasi dua arah antara perujuk dan tujuan rujukan, terutama dalam mengupayakan pelayanan kesehatan yang berkelanjutan $[5,6]$. Kurang terkontrolnya kunjungan pasien ke fasilitas kesehatan yang lebih tinggi (sekunder dan tersier) dapat berdampak pada biaya pelayanan yang lebih tinggi, pasien mendapatkan fasilitas rujukan yang kurang tepat, dan kurangnya distribusi beban pelayanan kesehatan [7,8]. Hal ini diperparah dengan ketiadaan informasi yang jelas terhadap ketersediaan sumber daya fasilitas kesehatan.

Ketersediaan informasi sumber daya fasilitas kesehatan diduga dapat meningkatkan kualitas pelayanan rujukan. Rujukan elektif kasus-kasus penyakit kronis dapat dilakukan di fasilitas yang tepat, informasi ketersediaan tempat tidur memudahkan dokter layanan primer untuk merujuk pasien, serta memungkinkan distribusi beban pelayanan kesehatan. Hal ini juga didukung dengan banyaknya fasilitas kesehatan yang telah menggunakan sistem informasi. Sebanyak 80\% rumah sakit di DI Yogyakarta sudah memiliki Sistem Informasi Manajemen Rumah Sakit (SIMRS), walaupun sebagian besar pemanfaatannya digunakan untuk laporan rutin [9]. Di level primer, puskesmas memiliki Sistem Informasi Manajemen Puskesmas (SIMPUS), sedangkan dokter praktek keluarga, dan klinik juga dibekali sistem informasi P-Care yang dikembangkan oleh BPJS Kesehatan (http://bpjs-kesehatan.go.id). Di beberapa daerah sudah mengembangkan sistem informasi pendukung SPGDT (Penanggulangan Gawat Darurat Terpadu) dengan konsep interoperabilitas untuk mendukung aksesibilitas layanan dan pelayanan rujukan. Sayangnya, penggunaannya masih sangat terbatas (http://spgdt.dinkesjatengprov.go.id/). Dengan keterbatasan tersebut, penelitian ini menjawab bagaimana sistem informasi yang telah ada dapat membantu mengatasi permasalahan pelayanan rujukan, terutama terkait dengan ketersediaan informasi sumber daya fasilitas kesehatan.

\section{Tinjauan Pustaka/Penelitian Sebelumnya}

Keterbatasan sarana dan prasarana merupakan masalah umum dalam pelayanan kesehatan di dunia. Berbagai upaya dilakukan untuk meningkatkan akses pelayanan kesehatan baik dari aspek infrastruktur, memperkuat sistem kesehatan melalui mekanisme pembiayaan, pelayanan rujukan, supply chain, distribusi tenaga kesehatan dan kebijakan. Teknologi informasi dan komunikasi juga mendapat perhatian khusus seiring dengan kemampuannya dalam mengintegrasikan sistem informasi kesehatan yang ada.

\subsection{Aksesibilitas Pelayanan Kesehatan}

Akses terhadap pelayanan kesehatan dapat diartikan sebagai kesesuaian antara kebutuhan masyarakat dan yang disediakan oleh sistem pelayanan kesehatan dalam konteks ketersediaan dan penggunaannya secara 
aktual. Ketersedian menjelaskan tentang pelayanan yang tersedia dan dapat diberikan kepada masyarakat, sedangkan penggunaan secara aktual menjelaskan tentang kenyataan pelayanan yang diterima oleh masyarakat yang membutuhkan. Terdapat lima dimensi yang mengidentifikasikan akses yaitu tersedianya layanan kesehatan (availability), kemudahan untuk mengakses (accessibility), fasilitas yang sesuai kebutuhan (accommodation), secara ekonomi terjangkau (affordability), dan dapat diterima oleh masyarakat atau acceptability [10].

Akses terhadap pelayanan kesehatan kemudian dikaitkan dengan konsep equity (keadilan). Konsep keadilan dalam pelayanan kesehatan dapat didefinisikan menghilangkan perbedaan pelayanan kesehatan yang diberikan kepada semua masyarakat. Equity berarti semua masyarakat mendapatkan persamaan dalam hal akses terhadap pelayanan kesehatan untuk kebutuhan yang sama, persamaan utilisasasi pelayanan kesehatan, dan persamaan outcome kesehatan [11]. Istilah equity dibedakan menjadi dua yaitu horizontal equity dan vertical equity. Horizontal equity berkaitan dengan pemberian pelayanan kesehatan yang sama untuk kebutuhan yang sama. Sedangkan vertical equity adalah pemberian pelayanan kesehatan yang disesuaikan dengan proporsi dan kebutuhan, atau dengan kata lain masyarakat yang memiliki kebutuhan lebih tinggi berhak mendapatkan pelayanan kesehatan yang lebih tinggi [12].

\subsection{Sistem Rujukan}

Sistem rujukan dikembangkan untuk meningkatkan aksesibilitas layanan kesehatan yang merata. Pelayanan kesehatan berdasarkan tingkatannya terdiri atas pelayanan kesehatan primer dan pelayanan kesehatan tingkat rujukan. Pelayanan kesehatan primer atau primary health care bertindak sebagai gatekeeper dimana terjadi kontak pertama secara perorangan atau masyarakat dengan pelayanan kesehatan. Bentuk pelayanan kesehatan primer ini antara lain puskesmas, klinik pratama, dan dokter praktik keluarga. Pelayanan kesehatan tingkat rujukan terdiri atas fasilitas kesehatan sekunder dan tersier. Bentuk pelayanan tingkat sekunder antara lain pelayanan kesehatan yang setara rumah sakit tipe C dan $\mathrm{D}$, sedangkan di tingkat tersier terdapat pelayanan kesehatan rumah sakit tipe A dan tipe B. Pelayanan kesehatan tingkat rujukan menerima rujukan dari tingkat pelayanan kesehatan di bawahnya [1].

Rujukan adalah pelimpahan wewenang dan tanggung jawab secara timbal balik, baik horizontal dan vertikal, maupun secara struktural dan fungsional terhadap kasus penyakit atau masalah penyakit atau permasalahan kesehatan. Sistem rujukan yang dipakai adalah sistem rujukan berjenjang dan teregional. Regionalisasi sistem rujukan adalah pengaturan sistem rujukan dengan penetapan batas wilayah administrasi daerah berdasarkan kemampuan pelayannan medis, penunjang, dan fasilitas pelayanan kesehatan yang terstruktur sesuai dengan kemampuan, kecuali dalam kondisi emergensi [13].

Sistem rujukan dapat berjalan dengan baik apabila faktor lain seperti pemerintah, teknologi, dan transportasi berjalan dengan baik. Untuk mendukung keberhasilan sistem rujukan diperlukan sistem rujukan dan sistem kesehatan yang baik, jumlah fasilitas rujukan yang cukup, kolaborasi pelayanan kesehatan antar-tingkat, sistem komunikasi dan transportasi, protokol rujukan, supervisi dan akuntabilitas kinerja penyedia layanan kesehatan, biaya layanan yang terjangkau, monitoring yang efektif dan dukungan kebijakan dari pemerintah [14].

\subsection{Sistem Penanggulangan Gawat Darurat Terpadu}

Sistem penanggulangan gawat darurat terpadu (SPGDT) adalah suatu sistem untuk menangani keadaan darurat baik keadaan darurat sehari-hari maupun dalam keadaan bencana. Komponen SPGDT terdiri atas call center, tim dispatch atau ambulan gawat-darurat, dan rumah sakit atau fasilitas kesehatan. Rumah sakit berperan penting dalam menyediakan data fasilitas yang tersedia di rumah sakit tersebut sehingga saat ada panggilan gawat darurat, petugas call center dapat dengan mudah mengarahkan ambulan gawat darurat menuju fasilitas kesehatan yang dituju. SPGDT sebagai suatu sistem terpadu penyelenggaraan 
kegawatdaruratan merupakan koordinasi dari berbagai unit kerja tidak hanya melibatkan dinas kesehatan dan rumah sakit, namun dapat juga melibatkan pihak lain seperti PMI, BPBD/BNPB (Badan Penanggulangan Bencana Daerah/Nasional), kepolisian, Dinas Perhubungan, dan sebagainya. Dengan adanya SPGDT ini, sistem rujukan juga diharapkan menjadi lebih baik seperti yang telah diatur dalam peraturan perundang-undangan [15].

\subsection{Model Sistem Informasi Terintegrasi}

Komunikasi pelayanan kesehatan pasien merupakan kunci penting pada sistem rujukan (rujukan dan feedback/follow up pasien). Teknologi informasi dapat digunakan untuk mengoptimalkan komunikasi antar fasilitas kesehatan. Sistem rujukan secara elektronik juga sudah diterapkan di beberapa negara $[16,17]$. Sistem rujukan ini menekankan mekanisme komunikasi dua arah, dimana data dan informasi pelayanan terhadap seorang pasien dipertukarkan secara elektronik. Berbagai model sistem informasi rujukan telah dikembangkan baik yang bersifat stand alone maupun yang terintegrasi. Bahkan komunikasi elektronik ini di beberapa negara dikembangkan secara terintegrasi melingkupi pertukaran data pada satu wilayah administrasi $[18,19]$.

Sayangnya, interoperabilitas antar sistem menjadi sulit dengan bervariasinya bahasa pemrograman, platform sistem dan sistem manajemen database yang digunakan di fasilitas kesehatan. Namun demikian, perkembangan teknologi khususnya web service dapat memfasilitasi komunikasi data elektronik, tanpa menimbulkan kekhawatiran dalam transmisi data, keamanan data, dan keterbatasan jaringan. Faktanya, beberapa perusahaan besar seperti Amazon, Facebook memanfaatkan web service untuk komunikasi data elektronik [20]. Praktik penggunaan sistem berbasis elektronik di Indonesia pun sudah terjadi antara BPJS Kesehatan dan rumah sakit. Bentuk integrasi ini berupa verifikasi kepesertaan, penerbitan surat eligibilitas pelayanan (SEP), klaim dan verifikasi pelayanan rumah sakit dan pemanfaatan sistem pencatatan medis. Beberapa inovasi lain juga berkembang di beberapa tempat. Sistem Informasi Penanggulangan Gawat Darurat Terpadu (SIM SPDGT), sistem penjadwalan rujukan online (SPRO), ketersediaan informasi ruang perawatan (Bed Online) dan sebagainya.

\section{Metodologi}

Penelitian dilakukan di Daerah Istimewa Yogyakarta (DIY) pada tahun 2015. Penelitian dilakukan secara kualitatif dengan pendekatan action research. Penelitian ini melibatkan pelayanan kesehatan primer dan lanjutan di DI Yogyakarta untuk menganalisa kebutuhan sistem informasi, mengembangkan prototipe sistem informasi terintegrasi dan menyediakan informasi sumber daya fasilitas kesehatan dalam mendukung pelayanan rujukan dan kegawat-daruratan medis. Analisis kebutuhan sistem diperoleh dari kunjungan lapangan, workshop dan diskusi kelompok terarah serta penyebaran kuesioner pada pelaku pelayanan kesehatan. Kunjungan lapangan dilakukan di 4 fasilitas kesehatan antara lain Puskesmas, klinik dokter keluarga, Klinik Pratama, dan Rumah Sakit Umum Daerah (RSUD). Selain untuk melihat proses bisnis pelayanan rujukan, kunjungan lapangan juga melihat inovasi sistem informasi yang sudah tersedia dalam mendukung pelayanan kesehatan. Workshop dan diskusi kelompok terarah melibatkan narasumber dari 14 rumah sakit serta 21 perwakilan dokter keluarga, klinik pratama dan Puskesmas di DI Yogyakarta untuk mendapatkan masukan mengenai solusi sistem informasi dalam permasalahan pelayanan rujukan. Kuesioner disebarkan kepada peserta workshop untuk mengetahui ketersedian sistem informasi dan sumber daya yang tersedia di fasilitas kesehatan.

\section{Hasil dan Pembahasan}

\subsection{Kebutuhan Informasi Terintegrasi}

Informasi sumber daya fasilitas kesehatan menjadi dasar dalam melakukan rujukan pasien ke rumah sakit 
atau fasilitas kesehatan lainnya. Selain pelayanan rujukan, pelayanan kegawat-daruratan medis juga memerlukan informasi yang sama. Informasi sumber daya yang jelas akan memudahkan tenaga kesehatan atau petugas call center SPGDT (Sistem Penanggulangan Gawat Darurat Terpadu) untuk menentukan fasilitas kesehatan yang paling tepat untuk penangan kasus tertentu. Setidaknya terdapat 5 pertimbangan dalam menyediakan informasi yang dibutuhkan untuk mendukung pelayanan rujukan di DI Yogyakarta, antara lain:

1) Lokasi dan regional fasilitas rujukan sesuai Peraturan Gubernur No 56 tahun 2012.

2) Informasi sumber daya fasilitas rujukan yang terdiri dari profil dan lokasi fasilitas kesehatan, ketersediaan tempat tidur, informasi jadwal rawat jalan spesialis dan sub-spesialis, informasi layanan penunjang medis

3) Informasi sumber daya fasilitas kesehatan yang valid dan tersedia secara real time.

4) Informasi sumber daya fasilitas kesehatan dapat diakses khususnya bagi tenaga kesehatan yang melakukan rujukan.

5) Dashboard dan pelaporan terkait dengan ketercukupan sumber daya fasilitas kesehatan.

Informasi ketersediaan tempat tidur merupakan informasi utama yang diperlukan secara real time untuk pelayanan rujukan baik vertikal (ke fasilitas yang lebih tinggi) maupun rujukan horizontal (ke fasilitas yang setipe) serta penanganan kegawat-daruratan medis [1]. Walaupun ketersediaan tempat tidur di DI Yogyakarta lebih dari cukup (menurut standar WHO 1:1.000 penduduk), yang sering terjadi justru sulitnya mencari tempat tidur untuk pasien yang membutuhkan fasilitas khusus seperti Intensive Care Init (ICU), Neonatal atau Pediatric Intencive Care Unit (NICU/PICU) dan ventilator atau alat bantu nafas. Keterbatasan informasi sumber daya tersebut menyulitkan tenaga kesehatan untuk merujuk pasien yang membutuhkan fasilitas tertentu. Selain itu, beberapa rumah sakit membatasi ketersediaan tempat tidur untuk pasien dengan skema jaminan kesehatan.

Penyediaan informasi sumber daya fasilitas kesehatan membutuhkan fasilitas pooling data yang dapat diakses secara mudah. Informasi sumber daya tersebut didapatkan dari masing-masing fasilitas kesehatan dan diintegrasikan sedemikian rupa sehingga menjadi sumber informasi yang komprehensif yang dapat diakses oleh pengguna yang membutuhkan. Namun demikian perbedaan pola penamaan sumber daya fasilitas kesehatan seperti nama ruang perawatan atau tempat tidur, kelas perawatan, nama poliklinik dan nama spesialisasi membutuhkan standardisasi terminologi yang baku. Standar terminologi diperlukan untuk mengintegrasikan informasi dari berbagai fasilitas pelayanan kesehatan yang berbeda.

\subsection{Potensi Integrasi Sistem Informasi}

Banyak faktor yang pendukung keberhasilan sistem rujukan seperti jumlah fasilitas kesehatan yang mencukupi, kolaborasi pelayanan kesehatan baik yang sama maupun yang berbeda level, teknologi informasi, sistem komunikasi dan transportasi, serta dukungan kebijakan dari pemerintah [14]. Teknologi informasi sangat berpotensi untuk dimaksimalkan perannya karena sebagian besar puskesmas dan rumah sakit di DI Yogyakarta sudah memiliki sistem informasi yang dikelola sendiri. Di level pelayanan dasar, fasilitas kesehatan sudah memiliki SIMPUS (Sistem Informasi Manajemen Puskesmas), SIM Klinik, dan P-care yang dikembangkan oleh BPJS. Lebih dari 85\% rumah sakit di DI Yogyakarta sudah memiliki Sistem Informasi Manajemen Rumah Sakit atau SIMRS. Beberapa diantara sistem tersebut memiliki data ketersediaan sumber daya fasilitas kesehatan yang dapat bermanfaat untuk mendukung pelayanan rujukan dan SPGDT [21].

Sayangnya, berdasarkan survey adopsi sistem informasi rumah sakit yang dilakukan Dinas Kesehatan tahun 2015, tingkat kedalaman penggunaan sistem informasi tersebut berbeda satu sama lainnya. Beberapa sistem hanya mengakomodasi fungsi front office untuk pendaftaran dan tagihan pasien. Sangat sedikit sistem informasi fasilitas kesehatan yang menyediakan fungsi penjadwalan dokter, manajemen tempat 
tidur, dan informasi fasilitas penunjang yang dimiliki. Secara spesifik hanya terdapat 12 rumah sakit yang memiliki sistem manajemen tempat tidur, dimana 3 diantaranya dapat dilihat melalui web [21].

Dinas Kesehatan DIY sudah mengembangkan Sistem Penanggulangan Kegawat-Daruratan Terpadu (SPGDT) untuk meningkatkan pelayanan kesehatan kepada masyarakat. Di daerah, pengembangan SPGDT diharapkan dapat menjadi public service center atau PSC [15], yang menyediakan layanan call center untuk penanggulangan gawat-darurat terpadu dan pelayanan rujukan di wilayah yang bersangkutan. Salah satu kebutuhan informasi pendukung SPGDT adalah ketersediaan sumber daya fasilitas kesehatan secara real time pada pelayanan gawat darurat [22]. Integrasi informasi dari berbagai sistem di fasilitas kesehatan seperti SIMRS, SIMPUS, SIM Klinik, dan P-Care diperlukan untuk menghasilkan informasi yang lengkap dan akurat. Beberapa daerah seperti DKI Jakarta, Provinsi Jawa Tengah, Kota Magelang, Kabupaten Salatiga telah memiliki sistem informasi terintegrasi yang dinamakan SIM SPGDT. Sistem informasi tersebut sangat diperlukan sebagai alat bantu operasional call center SPGDT atau PSC di DI Yogyakarta, khususnya dalam menyediakan informasi sumber daya fasilitas kesehatan.

Secara formal juga terdapat instruksi Kementrian Kesehatan untuk menyediakan informasi ketersediaan tempat tidur bagi semua fasilitas kesehatan yang memiliki rawat inap. Setidaknya informasi ruang perawatan kelas 1, 2 dan 3 serta ruang ICU (intensive care unit) harus disediakan sebagai salah satu fungsi keterbukaan informasi publik. Hal ini juga direkomendasikan oleh BPJS Kesehatan sebagai bagian dari proses kredensial fasilitas kesehatan, terutama rumah sakit untuk selalu menyediakan informasi ketersediaan tempat tidur agar dapat diakses oleh peserta BPJS Kesehatan. Khusus di DIY, terdapat peraturan Gubernur terkait Regionalisasi Rujukan, dimana informasi ketersediaan sumber daya fasilitas kesehatan menjadi salah satu pertimbangan dalam pelayanan rujukan. Dengan demikian, integrasi informasi sumber daya fasilitas kesehatan sangat diperlukan untuk mendukung pelayanan rujukan dan kegawat-daruratan medis.

\subsection{Prototipe Sistem Informasi Terintegrasi}

Untuk memfasilitasi integrasi data sumber daya fasiltias kesehatan dan memberikan layanan informasi yang sesuai, perlu dikembangkan sistem informasi terintegrasi atau di beberapa tempat disebut SIM SPGDT. Prototipe dikembangkan berdasarkan analisa kebutuhan yang dilakukan, dimana desain arsitektur-nya disesuaikan dengan kondisi lapangan. Rancangan tabel, desain tampilan dan fungsi layanan informasi juga disesuaikan dengan potensial pengguna.

\subsubsection{Sistem Requirement}

Secara umum sistem informasi terintegrasi merupakan portal layanan yang menerima informasi dari fasilitas kesehatan untuk diintegrasikan (data pooling) dan memberikan layanan informasi kepada penggunanya. Secara konseptual sistem informasi terintegrasi ini dapat dapat dilihat di Gambar 1. Beberapa fungsi dalam portal sistem terintegrasi antara lain:

1) Menyimpan dan menyediakan informasi profil fasilitas kesehatan

2) Integrasi informasi ketersediaan tempat tidur secara real time dan menyediakan informasi ketersediaan tempat tidur secara online.

3) Menyimpan dan menampilkan informasi jadwal praktek dokter dan dokter spesialis di fasilitas kesehatan.

4) Menyimpan dan menyediakan informasi fasilitas penunjang.

Sedangkan pengguna sistem informasi terintegrasi ini dapat dikategorikan menjadi 4 kelompok, yaitu:

1) Administrator sistem untuk mengelola standar data dalam rangka memastikan penggunaan standar 
dalam sistem informasi terintegrasi.

2) Tenaga kesehatan di fasilitas kesehatan semua level (Puskesmas, Klinik, Dokter Keluarga dan Rumah sakit). Tenaga kesehatan berperan untuk mengupdate informasi sumber daya fasilitas kesehatan yang dimiliki seperti ketersediaan tempat tidur, jadwal praktek dokter dan fasilitas penunjang yang dimiliki. Tenaga kesehatan juga dapat mengakses informasi sumber daya kesehatan melalui modul pencarian yang disediakan. Beberapa fasilitas kesehatan yang memiliki sistem informasi elektronik dapat memanfaatkan fasilitas web service sistem informasi terintegrasi untuk mengambil informasi sumber daya fasilitas kesehatan di DIY.

3) Call center SPGDT/PSC (Public Service Center) dan Call Center BPJS untuk mencari ruang perawatan yang tersedia dalam penanganan kasus kegawat-daruratan atau kebutuhan pelayanan rujukan. Pada kasus gawat darurat medis seperti kecelakaan lalu lintas, petugas call center SPGDT (Sistem Penanggulangan Gawat Darurat Terpadu) akan menerima panggilaan dan melakukan triase (penilaian medis) terhadap korban melalui penelpon. Selain mengkoordinasi pengiriman ambulan, petugas call center juga akan mengidentifikasi ketersediaan sumber daya fasilitas kesehatan yang sesuai dengan kasus yang terjadi. Petugas call center dapat mengakses sistem informasi terintegrasi sehingga dapat menentukan fasilitas yang tepat bagi penanganan kegawat-daruratan medis.

4) Masyarakat umum, terutama informasi terkait regionalisasi fasilitas kesehatan, data agregat ketersediaan tempat tidur, jadwal praktik dokter spesialisasi dan dokter layanan primer. Aksesibilitas bagi masyarakat umum memudahkan dalam merencanakan pelayanan kesehatan yang diinginkan. Namun demikian, tidak semua informasi dapat diakses oleh masyarakat umum karena berkaitan dengan wewenang dan validitas informasi.

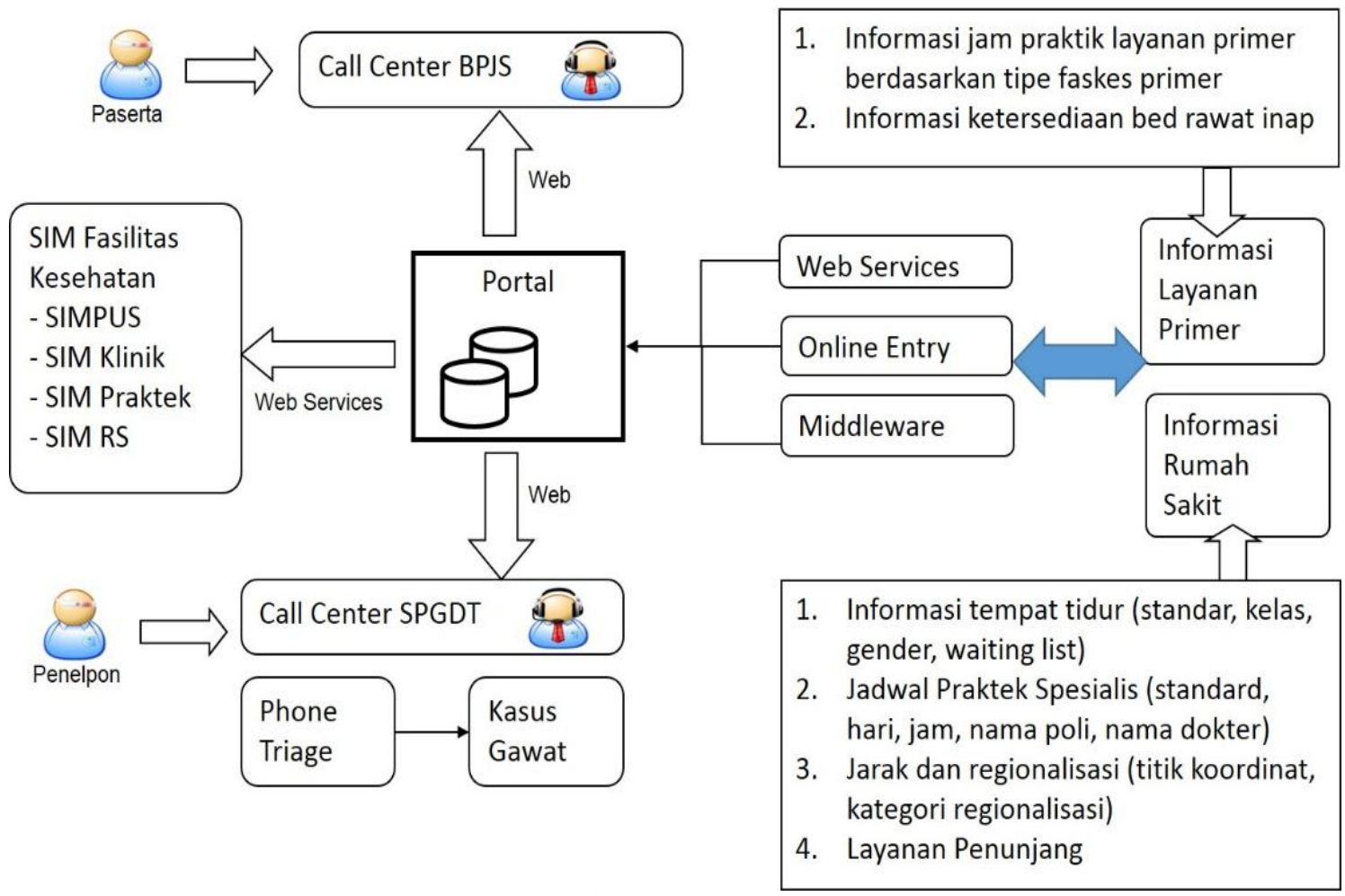

Gambar 1. Bagan interkoneksi antar sistem informasi di DI Yogyakarta

Kebutuhan khusus dari sistem ini adalah mengakomodasi standar data fasilitas pelayanan kesehatan yang terdiri dari 5 aspek, yaitu: 
1) Identitias fasilitas kesehatan sesuai kodefikasi standar, kelas, regional, titik koordinat. Identitas fasilitas kesehatan dapat mengacu pada kode rumah sakit dan puskesmas dari Kementrian Kesehatan, sedangkan kode klinik dan layanan primer dari BPJS Kesehatan.

2) Standar nama ruang perawatan (rawat inap). Rawat inap di fasilitas kesehatan umumnya mempertimbangkan kelas dan spesialisasi (ruang perawatan bedah, anak dan lainnya).

3) Standar nama rawat jalan atau poliklinik umum, spesialis dan sub-spesialisasi.

4) Standar nama regionalisasi rujukan. Menurut Pergub DI Yogyakarta terdapat beberapa regionalisasi pelayanan rujukan yang mempertimbangkan distribusi beban pelayanan kesehatan, lokasi kedekatan dan tipe rumah sakit.

5) Standar nama penyedia layanan kesehatan (dokter, gelar, spesialisasi, jam praktek).

\subsubsection{Desain Arsitektur Sistem Terintegrasi}

Integrasi antar sistem ditutamakan untuk mengakomodasi informasi ketersediaan tempat tidur, khususnya dari rumah sakit yang terdapat di DI Yogyakarta. Hal ini dikarenakan informasi ketersediaan tempat tidur sangat dinamis, informasi tempat tidur paling dibutuhkan untuk pelayanan rujukan dan kegawat-daruratan medis, secara regulasi direkomendasikan bagi semua fasilitas kesehatan yang memiliki rawat inap dan beberapa fasilitas kesehatan telah memiliki sistem informasi manajemen tempat tidur. Hasil responnya, REST mengeluarkan data berupa XML atau JSON. Secara sederhana desain arsitektur yang dibuat dapat dilihat pada Gambar 2 berikut:

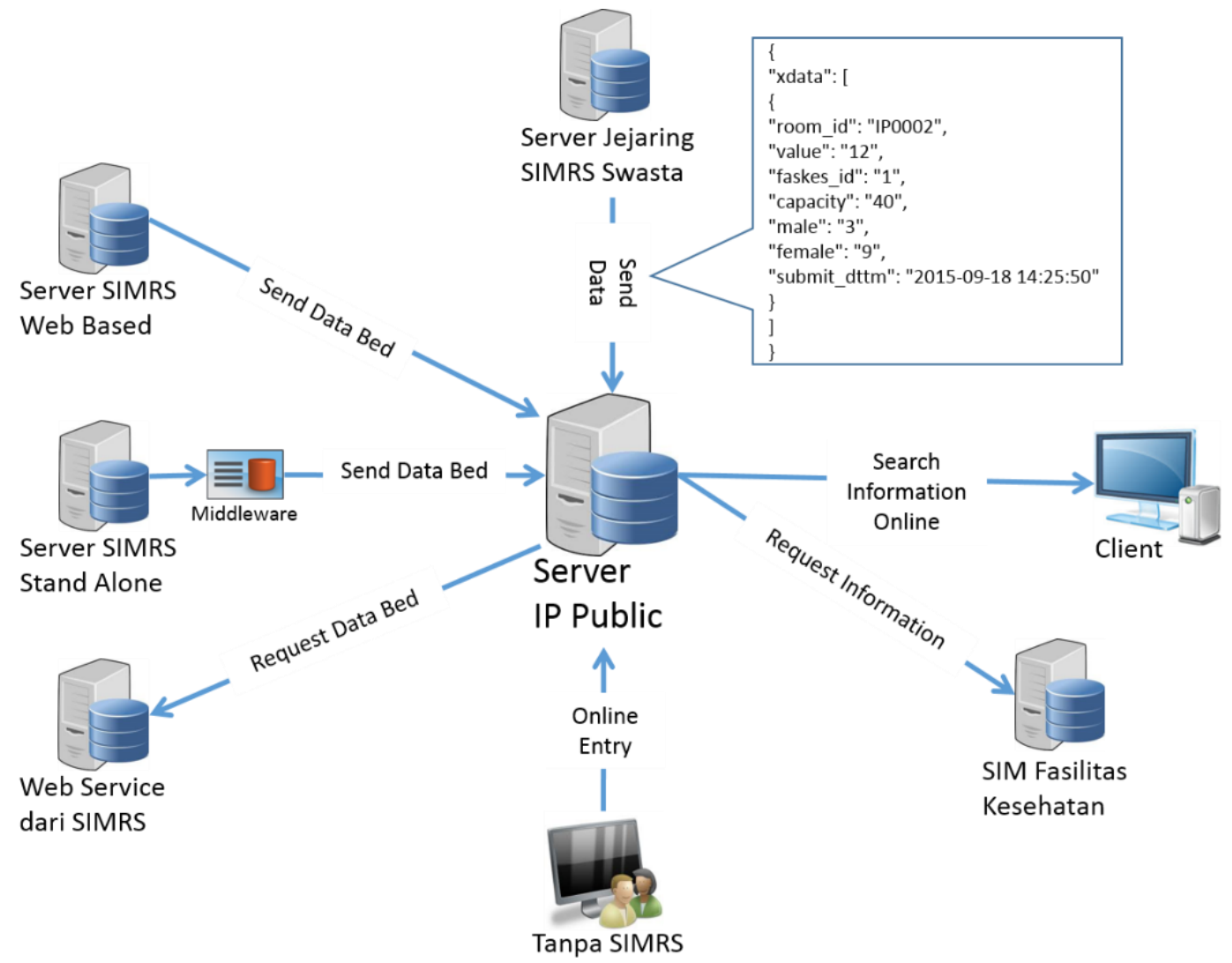

Service Update Data

Service Request Data

Gambar 2. Desain arsitektur sistem informasi terintegrasi 
Prototipe sistem informasi terintegrasi dikembangkan berbasis web dan diinstal di sebuah server dengan IP Publik. Untuk mendukung integrasi antar sistem yang berbeda, komunikasi data meggunakan pendekatan RESTFul web services. Service method yang digunakan dalam REST antara lain GET, PUT, POST, dan DELETE [23,24]. Hasil responnya, REST mengeluarkan data berupa XML atau JSON. Untuk mendukung komunikasi data elektronik, dibuat kesepakatan terhadap standar data, unik ID rumah sakit dan struktur message yang dikirimkan (Gambar 2), dimana sistem informasi rumah sakit perlu menyesuaikan. Proses mapping terhadap standar data dilakukan oleh masing-masing rumah sakit, termasuk membuat fasilitas web service untuk mengirimkan data atau menyediakan layanan web service bagi sistem informasi terintegrasi. Bagi rumah sakit yang belum memiliki sistem informasi manajemen tempat tidur, mekanisme update secara online juga disediakan dengan akses langsung ke sistem informasi secara individual. Selain itu, fasilitas pencarian secara online juga dapat dilakukan dengan mengakses web sistem informasi terintegrasi.

\subsubsection{Integrasi Antar Sistem Informasi}

Terdapat dua kelompok layanan yang dibuat untuk pengintegrasian sistem yaitu Service update data dan 2). Service request data. Service update data diatur setiap 2 jam untuk mengirimkan data atau mengambil data ketersediaan tempat tidur dari rumah sakit yang memiliki sistem informasi manajemen tempat tidur. Adanya variasi sistem informasi rumah sakit, mengharuskan penggunaan mekanisme integrasi dengan beberapa pendekatan, yaitu:

1) SIM Rumah Sakit (SIMRS) yang berbasis web mengirimkan data langsung ke Server dengan standar format XML atau JSON. Untuk dapat mengirimkan data, rumah sakit perlu melakukan mapping terhadap standar data dan menambahkan fasilitas web service untuk mengirimkan data dalam format JSON atau XML.

2) Beberapa rumah sakit tergabung dalam asosiasi rumah sakit swasta yang memiliki fasilitas sistem manajemen tempat tidur bersama. Sistem ini berbasis web yang kemudian ditambahkan fungsi untuk mengirimkan data ketersediaan tempat tidur ke Server.

3) SIMRS yang berbasis desktop (stand alone) mengirimkan data ke middleware yang berupa aplikasi berbasis web dan database sederhana. Middleware diatur untuk mengirimkan data secara regular ke Server yang sudah diatur berdasarkan standar data dan format yang telah disepakati.

4) SIMRS menyediakan web service dengan format yang telah disepakati. Server secara reguler mengambil data ke SIMRS melalui fasilitas web service yang justru disediakan oleh rumah sakit.

Untuk pendekatan nomor 1, 2 dan 3, variabel yang dibutuhkan dalam sistem adalah webservice menggunakan REST webservice, URL target service di http://<server $>/<$ aplikasi $>$ index.php/api/go/send serta bentuk format data yang telah disepakati dengan contoh format JSON sebagai berikut:

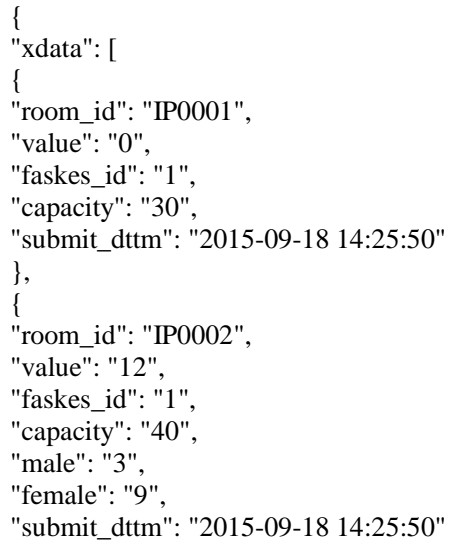


Keterangan:

- $\quad x d a t a$ adalah variabel yang akan dibaca oleh sistem

- $\quad$ room_id adalah kode ruang yang dikenali oleh sistem berdasarkan standar yang telah disepakati

- value adalah variable yang berisi jumlah tempat tidur yang tersedia atau kosong

- $\quad$ faskes_id adalah ID unik yang akan dibaca oleh sistem

- capacity adalah jumlah total tempat tidur yang tersedia

- $\quad$ submit_dttm adalah waktu data dikirim dengan format yyyy-mm-dd hh:mm:ss

- $\quad$ male dan female adalah optional, terutama jika alokasi tempat tidur membedakan jenis kelamin

Sampai saat ini dalam pengembangan proses integrasi menggunakan web service belum menggunakan model keamanan yang optimal.

Service request data juga difasilitasi dengan pendekatan web service. Fasilitas kesehatan yang sudah memiliki sistem informasi dapat memanfaatkan layanan web service ini untuk mendapatkan informasi ketersediaan tempat tidur di DI Yogyakarta. Namun demikian, sistem informasi di fasilitas kesehatan perlu menambahkan fungsi untuk memanfaatkan layanan web service yang diberikan. Berikut ini adalah 2 contoh untuk mengakses data sumber daya fasilitas kesehatan dari sistem informasi terintegrasi

1) Untuk mendapatkan data ketersediaan tempat tidur dari sistem informasi terintegrasi dengan fasilitas web service berikut: http://<server>/<aplikasi>/index.php/api/go/ketersediaan untuk format XML atau http:/<server>/<aplikasi>/index.php/api/go/ketersediaan/format/json untuk format JSON

2) Untuk mendapatkan data jadwal dokter dari sistem informasi terintegrasi dangan fasilitas web service berikut: http://<server>/<aplikasi>/index.php/api/go/getjadwaldokter untuk format XML atau http://<server>/<aplikasi>/index.php/api/go/getjadwaldokter/format/json untuk format JSON

\subsubsection{Rancangan Tabel}

MySQL digunakan sebagai database management systems (DBMS) pada prototipe sistem informasi terintegrasi. Beberapa tabel transaksi utama yang digunakan dalam sistem informasi terintegrasi ini dapat dilihat pada Gambar 3. Tabel utama tersebut antara lain:

1) Tabel fasilitas kesehatan (ref_faskes) sebagai tabel utama untuk transaksi profil fasilitas kesehatan. Data titik koordinat, regionalisasi fasilitas kesehatan terdapat di dalam tabel ini.

2) Tabel ketersediaan (tb_availability) untuk update informasi ketersediaan tempat tidur

3) Tabel jadwal praktek dokter (tb_doctor_sch3) untuk transaksi jadwal dokter spesialis dan sub spesialis

4) Tabel fasilitas penunjang (tb_fasilitaspenunjang) untuk transaksi fasilitas penunjang yang dimiliki oleh fasilitas kesehatan.

\subsubsection{Desain Tampilan}

Bahasa pemrograman PHP digunakan untuk membuat prototipe dengan framework CodeIgniter (CI). Desain tampilan depan (home) memberikan gambaran distribusi fasilitas kesehatan dan ketersediaan tempat tidur di DI Yogyakarta seperti yang terlihat pada Gambar 4. Peta persebaran fasilitas pelayanan kesehatan dibuat berdasarkan titik koordinat pelayanan kesehatan dan tipe fasilitas kesehatan (layanan primer dan layanan lanjutan). Informasi yang dapat ditampilkan dalam visual peta tersebut antara lain tipe 
fasilitas kesehatan (layanan primer, sekunder, tersier), alamat dan nomor telepon fasilitas kesehatan. Sistem informasi terintegrasi juga menampilkan indikator ketercukupan tempat tidur di DI Yogyakarta berdasarkan jumlah populasi dan peserta BPJS Kesehatan per kabupaten/kota.

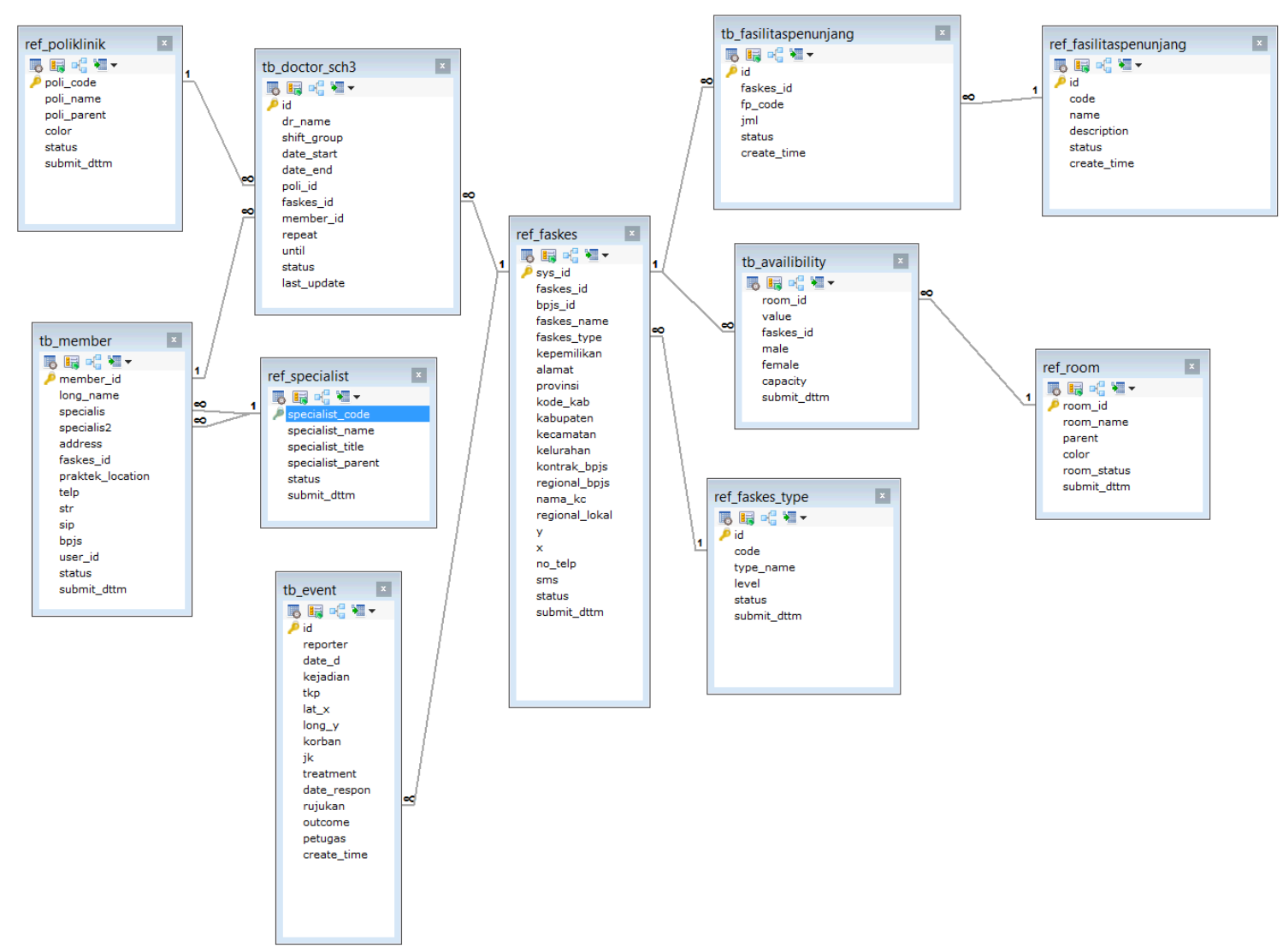

Gambar 3. Entity Relationship Diagram Sistem Informasi Terintegrasi

Data transaksi utama terdiri dari data profil fasilitas kesehatan, ketersediaan tempat tidur, jadwal praktek dokter dan dokter spesialis serta informasi fasilitas penunjang. Sayangnya, integrasi antar sistem informasi baru sebatas pada informasi ketersediaan tempat tidur. Data yang diperlukan meliputi nama ruang perawatan, kapasitas tempat tidur yang dimiliki RS berdasarkan kelas, jumlah tempat tidur yang tersedia, pembagian berdasarkan jenis kelamin serta tanggal dan jam update terakhir (Gambar 5).

\subsubsection{Fungsi Layanan Informasi}

Selain ketersediaan tempat tidur, terdapat beberapa fungsi layanan yang disediakan dari sistem informasi terintegrasi ini. Layanan pencarian fasilitas kesehatan yang mengkombinasikan sumber daya fasilitas kesehatan tertentu. Output pencarian dalam bentuk daftar dan lokasi fasilitas kesehatan yang ditampilkan dalam peta (Gambar 6).

Layanan pencarian fasilitas kesehatan berdasarkan wilayah dan ketersediaan fasilitas penunjang ditampilkan dalam bentuk daftar dan lokasi rumah sakit berdasarkan titik koordinat. Pengguna memiliki alternatif untuk melakukan pelayanan pasien rujukan elektif (non-emergency). Fungsi lain dan yang paling 
utama adalah layanan pencarian tempat tidur sesuai dengan kelas perawatan, spesialisasi dan ketersediaannya. Melalui informasi tersebut tenaga kesehatan akan terbantu dalam menangani pasien rujukan melalui adanya kepastian perawatan di fasilitas kesehatan yang tepat.

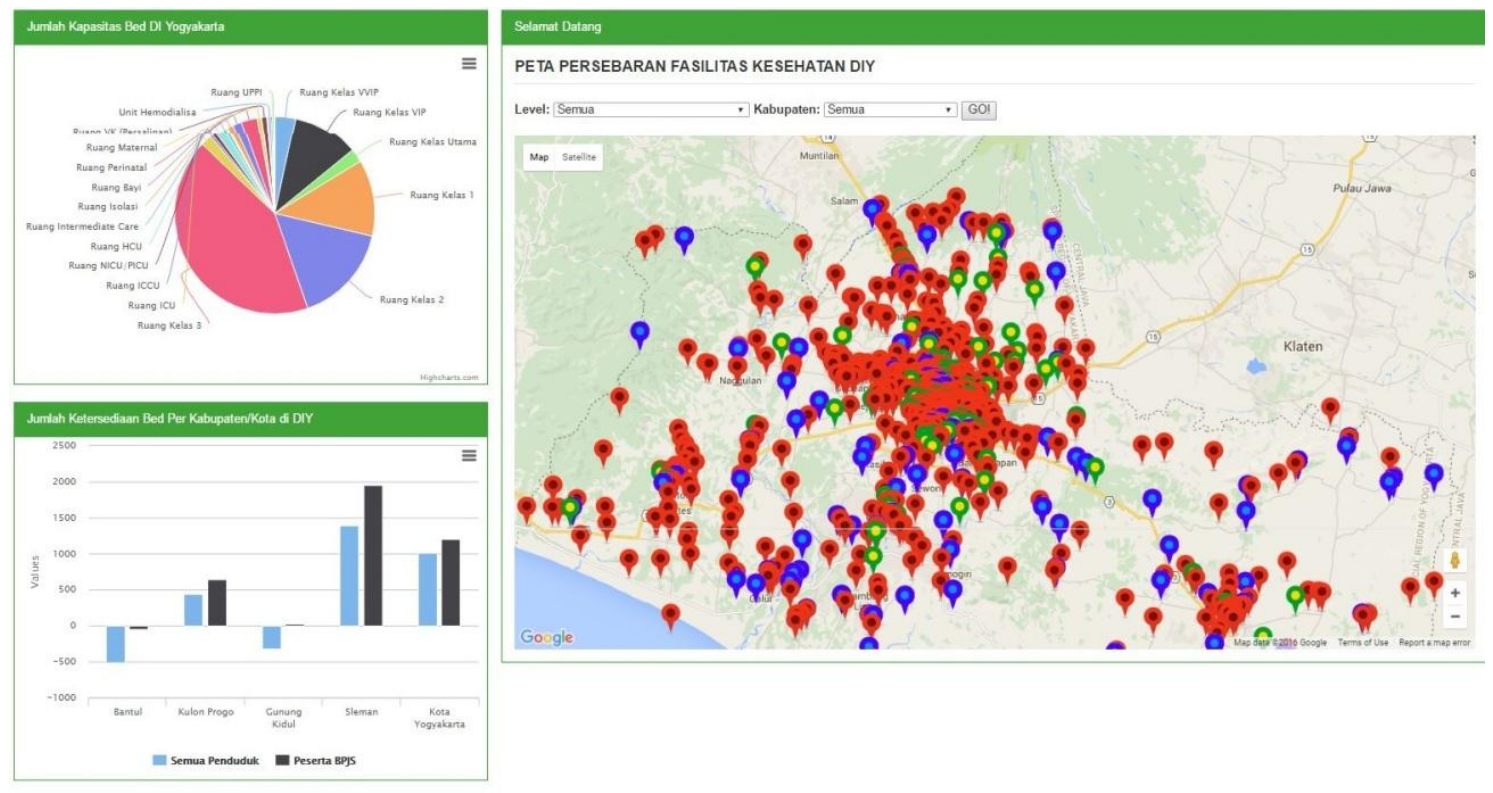

Gambar 4. Desain Tampilan Depan (home) Sistem Informasi Terintegrasi

\begin{tabular}{|c|c|c|c|c|c|c|c|}
\hline \multirow[t]{3}{*}{ No. } & \multirow[t]{3}{*}{ Nama Ruang } & \multicolumn{5}{|c|}{ Jumlah Bed } & \multirow[t]{3}{*}{ Last Updated } \\
\hline & & \multirow[t]{2}{*}{ Kapasitas } & \multirow[t]{2}{*}{ Terpakai } & \multicolumn{3}{|c|}{ Tersedia } & \\
\hline & & & & Total & $\mathrm{L}$ & $P$ & \\
\hline 1 & Ruang Kelas VIP & 13 & 7 & 6 & 0 & 0 & $2016-06-3009: 51: 5$ \\
\hline 2 & Ruang Kelas Utama & 17 & 6 & 11 & 0 & 0 & $2016-06-3009: 51: 5$ \\
\hline 3 & Ruang ICU & 4 & 4 & 0 & 0 & 0 & $2016-06-3009: 51: 5$ \\
\hline 4 & Ruang Bayi & 18 & 2 & 16 & 0 & 0 & $2016-06-3009: 51: 5$ \\
\hline 5 & Kelas 1 detail & 16 & 11 & 5 & 0 & 0 & $2016-06-3009: 51: 5$ \\
\hline 6 & Kelas 2 detail & 22 & 14 & 8 & 0 & 0 & $2016-06-3009: 51: 5$ \\
\hline 7 & Kelas 3 detail & 65 & 41 & 24 & 0 & 0 & $2016-06-3009: 51: 5$ \\
\hline
\end{tabular}

Gambar 5. Contoh output informasi ketersediaan tempat tidur di sistem informasi terintegrasi 

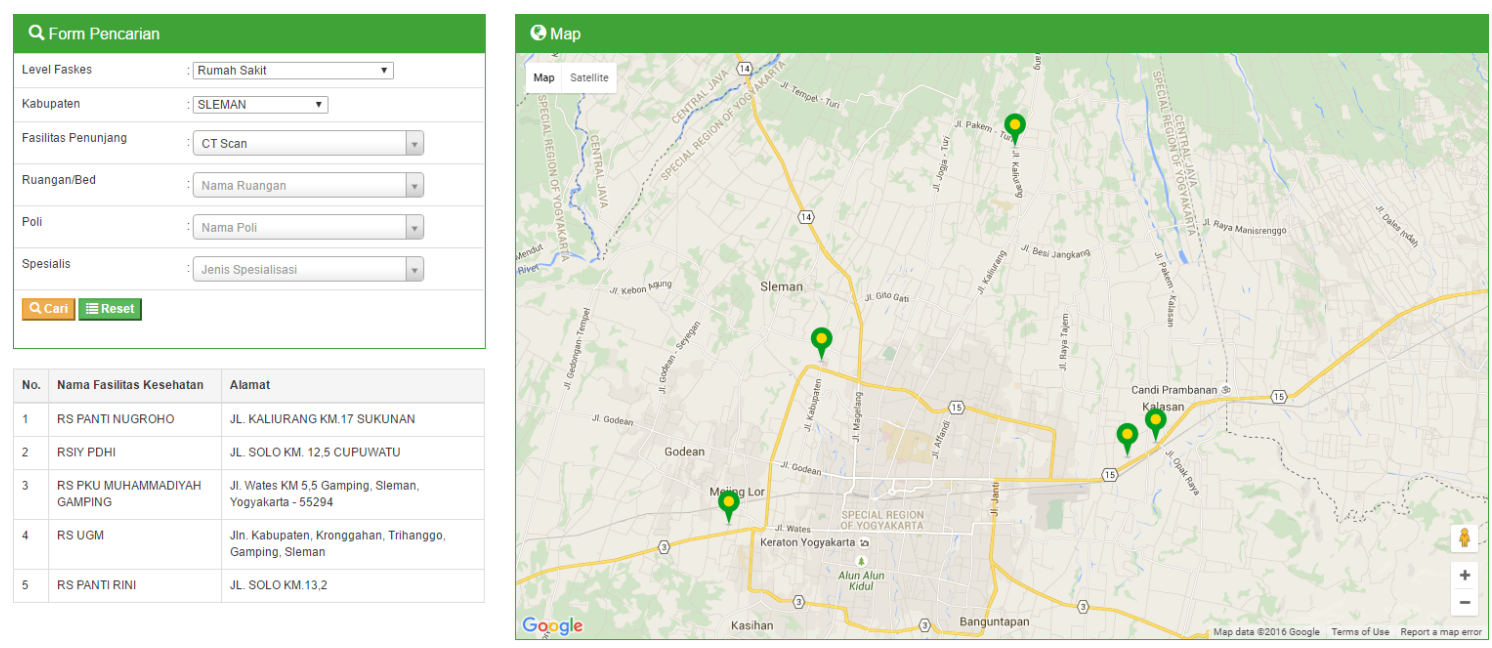

Gambar 6. Contoh output layanan pencarian fasilitas kesehatan berdasarkan ketersediaan sumber daya fasilitas kesehatan.

\section{Kesimpulan}

Penelitian ini menunjukkan bahwa teknologi informasi dan komunikasi dapat memfasilitasi komunikasi data antar sistem informasi yang berbeda. Penelitian ini juga menjawab pertanyaan potensi integrasi sistem informasi untuk mendukung pelayanan kesehatan di suatu wilayah.

\subsection{Simpulan}

Sistem informasi terintegrasi dikembangkan sebagai alat bantu untuk pelayanan rujukan dan bahkan untuk mendukung pelayanan kegawat-daruratan medis di DI Yogyakarta. Berbagai faktor mendorong perlunya sistem informasi terintegrasi untuk mengumpulkan, mengolah dan menyajikan informasi bagi tenaga kesehatan. Perannya adalah memberikan layanan informasi sumber daya fasilitas kesehatan, terutama ketersediaan tempat tidur di rumah sakit. Sistem ini merupakan bagian dari Sistem SPGDT yang dikembangkan oleh Dinas Kesehatan DIY. Banyaknya fasilitas pelayanan kesehatan yang sudah menggunakan sistem informasi elektronik memberikan peluang untuk integrasi antar sistem menggunakan pendekatan web service. Sayangnya perlu adanya kesepekatan penggunaan standar terminologi sehingga integrasi dari berbagai sumber data dapat dilakukan secara elektronik.

\subsection{Saran}

Sistem informasi terintegrasi merupakan upaya untuk memaksimalkan peran teknologi informasi dan komunikasi untuk mengatasi permasalahan pelayanan rujukan. Pengembangan sistem informasi terintegrasi perlu memperhatikan penggunaan standar data (penamaan tempat tidur, penamaan poliklinik spesialisasi) dan standar operasional prosedur dengan mengakomodasi prinsip-prinsip interoperabilitas. Informasi sumber daya fasilitas kesehatan yang tersedia dapat dimanfaatkan tidak hanya untuk pelayanan rujukan dan SPGDT, tetapi dapat digunakan juga untuk pemantauan terhadap kinerja fasilitas kesehatan bagi Dinas Kesehatan dan BPJS Kesehatan. Kelengkapan data menjadi alasan pembatasan akses bagi masyarakat umum untuk mencegah kesalahan interpretasi. Untuk meningkatkan validitas data, perlu didukung oleh regulasi dalam mengintegrasikan sistem informasi yang sudah ada di fasilitas kesehatan. Selain itu, dengan adanya regulasi akan jelas peran pihak-pihak yang terlibat dalam sistem sehingga memudahkan proses integrasi. 


\section{Daftar Rujukan}

[1] Kementrian Kesehatan. Permenkes No. 001 Tahun 2012 Tentang Sistem Rujukan Pelayanan Kesehatan Perorangan. Jakarta, Indonesia; 2012.

[2] Konsil Kedokteran Indonesia. Standar Kompetensi Dokter Indonesia. Jakarta: Konsil Kedokteran Indonesia; 2012.

[3] Gubernur Daerah Istimewa Yogyakarta. Pergub No. 59 Tahun 2012 Tentang Pedoman pelaksanaan Sistem Rujukan Pelayanan kesehatan. Indonesia; 2012 p. 1 of 44.

[4] BPJS Kesehatan. Rujuk Balik di Era JKN [Internet]. BPJS Kesehat. 2014 [cited 2016 Mar 31]. Available from: http://www.bpjs-kesehatan.go.id/bpjs/index.php/post/read/2014/261/Rujuk-Balik-di-Era-JKN/berita

[5] Gandhi TK, Sittig DF, Franklin M, Sussman AJ, Fairchild DG, Bates DW. Communication Breakdown in the Outpatient Referral Process. J Gen Intern Med. 2000;15:626-31.

[6] Reid RJ, Wagner EH. Strengthening primary care with better transfer of information. CMAJ. 2008;179:987-8.

[7] Forum Kompas. Tiap Hari 30 Pasien RSCM Tak Tertangani Karena Penuh. Forum Kompas Online. 2012.

[8] Chen L-C, Schafheutle EI, Noyce PR. The impact of nonreferral outpatient co-payment on medical care utilization and expenditures in Taiwan. Res. Soc. Adm. Pharm. 2009;5:211-24.

[9] Hariana E, Rahmanti AR, Sanjaya GY, Murtiningsih B, Nugroho E. Penggunaan sistem informasi manajemen rumah sakit (SIMRS) di DI Yogyakarta. Semin. Nas. Sist. Inf. Indones. Denpasar, Bali: SESINDO; 2013.

[10] Penchansky R, Thomas JW. The Concept of Access Definition and Relationship to Consumer Satisfaction. Med. Care. 1981;19:127-40.

[11] Oliver A, Mossialos E. Equity of access to health care: outlining the foundations for action. J. Epidemiol. Community Health [Internet]. $2004 \quad$ [cited $2014 \quad$ Oct $\quad 27] ; 58: 655-8 . \quad$ Available from: http://www.pubmedcentral.nih.gov/articlerender.fcgi?artid=1732867\&tool=pmcentrez\&rendertype=abstract

[12] Ozegowski S, Sundmacher L. Understanding the gap between need and utilization in outpatient care--the effect of supply-side determinants on regional inequities. Health Policy [Internet]. Elsevier Ireland Ltd; 2014 [cited 2014 Sep 25];114:54-63. Available from: http://www.ncbi.nlm.nih.gov/pubmed/24016773

[13] Departemen Kesehatan. Sistem Kesehatan Nasional. Jakarta; 2009.

[14] Murray SF, Pearson SC. Maternity referral systems in developing countries: current knowledge and future research needs. Soc. Sci. Med. [Internet]. 2006 [cited 2012 May 15];62:2205-15. Available from: http://www.ncbi.nlm.nih.gov/pubmed/16330139

[15] Sylvana B. Sistem Penanggulangan Gawat Darurat Terpadu (SPGDT) Melalui Call Center 119 dan PSC. Yogyakarta: Forum Informatika Kesehatan Indonesia; 2015.

[16] Heitmann KU, Schweiger R, Dudeck J. Discharge and referral data exchange using global standards- the SCIPHOX project in Germany. Int. J. Med. Inform. [Internet]. 2003;70:195-203. Available from: http://www.sciencedirect.com/science/article/pii/S1386505603000364

[17] Takeda H, Matsumura Y, Kuwata S, Nakano H, Shanmai J, Qiyan Z, et al. An assessment of PKI and networked electronic patient record system: lessons learned from real patient data exchange at the platform of OCHIS (Osaka Community Healthcare Information System). Int. J. Med. Inform. 2004;73:311-6.

[18] Kaelber DC, Bates DW. Health information exchange and patient safety. J. Biomed. Inform. [Internet]. 2007 [cited 2012 May 25];40:S40-5. Available from: http://www.ncbi.nlm.nih.gov/pubmed/17950041

[19] Kern LM, Kaushal R. Health information technology and health information exchange in New York State: new initiatives in implementation and evaluation. J. Biomed. Inform. [Internet]. 2007 [cited 2012 Apr 24];40:S17-20. Available from: http://www.ncbi.nlm.nih.gov/pubmed/17945542

[20] Zhang JK, Xu W. Web Service-based Healthcare Information System (WSHIS): A case study for system interoperability concern in healthcare field. ICBPE 2006 - Proc. 2006 Int. Conf. Biomed. Pharm. Eng. Singapore; 2006. p. 588-94.

[21] Dinas Kesehatan DIY. Evaluasi Sistem Informasi Rumah Sakit di DI Yogyakarta. Yogyakarta; 2015.

[22] Prawira MA, Noor I, Nurani F, Publik JA, Administrasi FI, Brawijaya U. Studi Kasus Call Center SPGDT 119 sebagai Layanan Gawat Darurat pada Dinas Kesehatan Provinisi DKI Jakarta. J. Adm. Publik. 2008;2:715-21.

[23] Daniel S, Przemyslaw T, Lars H. Integrating Information Systems Using Web Oriented Integration Architecture and RESTful Web Services. 2010 6th World Congr. Serv. Ieee; 2010;598-605.

[24] Istiyanto JE, Sutanta E. Model Interoperabilitas Antar Aplikasi E-Government. J. Teknol. Technoscientia. 2012;4:137-48. 